\title{
Interference Impact on the Performance of UWB Communication Systems
}

\author{
E.M. Shaheen ${ }^{*}$
}

Abstract: This paper evaluates the bit error rate performance of a ultra-wideband (UWB) communication system under the impact of both multiple access and narrowband interferences operating in additive white Gaussian noise (AWGN) channels. The narrowband interference (NBI) signal is modeled as the IEEE802.11a signal, which can be approximated by the sum of independent asynchronous tone interferers with arbitrary frequencies.

Multiple access interference is assumed a zero mean Gaussian process, where it has been investigated in both perfect and imperfect power control scenarios. It will be shown that the performance of a UWB system is severely deteriorated due to the presence of both types of interference, yet the NBI has more impact on the performance of UWB communication systems compared to the multiple access one.

Keywords: Ultra-wideband, Narrow band interference, IEEE802.11a, multiple access interference.

\section{Introduction}

UWB is a promising technology which has emerged for high data rate, low power, and low cost short range wireless communication systems. UWB signals must have bandwidths of greater than $500 \mathrm{MHz}$ or a fractional bandwidth larger than $20 \%$ at all times of transmission. The Federal Communications Commission (FCC) government agency specifies $7.5 \mathrm{GHz}$ of spectrum between 3.1 and $10.6 \mathrm{GHz}$ for unlicensed use of the UWB communication and measurement systems [1].

In order to reduce the interference to existing narrowband systems, the FCC also imposed a power restriction on UWB communication systems, where the power spectral density levels are limited to $-41.3 \mathrm{dBm} / \mathrm{MHz}$. However, narrowband signals that exist in the UWB range may exhibit a high power spectral density (PSD) levels compared to the PSD of UWB signals as seen by a UWB receiver. As a result, one would expect a degradation of the UWB bit error rate (BER) performance

Also, in order to evaluate the performance of UWB communication systems, it is important to estimate its ability to work in multi user environment. Even if UWB communication systems are designed for indoor application, it seems to be still important to guarantee the coexistence of a large number of transmitters in the covered area.

Previous work on the performance analysis of UWB communication systems in the presence of NBI focused on additive white Gaussian noise (AWGN) channels. For example, a study of UWB communications in the presence of jamming was presented in [2]. In this work the performance of a single-user UWB system with a jamming signal was analyzed and closed form expressions for the jamming resistance of time-hopping pulse position (TH-PPM)

\footnotetext{
*Eyptian Armed Forces, efareed2007@yahoo.com
} 
modulation utilizing rectangular pulse-shaping were reported. The jamming signal used in [2] was also assumed to be a pass-band Gaussian noise.

Multiple access performance assuming free space propagation conditions and AWGN are studied in [3] for both analog and digital modulation techniques, in which the performance computation is based on signal to noise ratio (SNR) analytic evaluation. The multiple access interference is modeled as a Gaussian random process. To this end, in this paper, we will investigate the performance of TH-PPM UWB communication systems in the presence of NBI along with multiple access interference in AWGN channels. We derive a simple, yet accurate formula for evaluating the BER performance of such systems in the presence of both types of interference.

The paper is organized as follows. The system model is described in section 2 . In section 3 the UWB BER performance is analyzed and a closed-form expression is given. Section 4 presents representative numerical results of system performance under various conditions and finally, section 5 draws the conclusions.

\section{System Model}

\section{A. The Desired Signal}

The transmitted TH-PPM UWB signal can be written as

$$
S_{p p m}^{k}(t)=\sqrt{E_{t x}^{k}} \sum_{j=-\infty}^{\infty} p\left(t-j T_{f}-C_{j}^{k} T_{c}-\delta d_{\left\lfloor j / N_{s}\right\rfloor}^{k}\right)
$$

where $S_{p p m}{ }^{k}(t)$ is the $k^{\text {th }}$ user's signal, $p(t)$ is the shape of the transmitted pulse with pulse width $\mathrm{T}_{\mathrm{m}}, \mathrm{d}_{[\mathrm{j} / \mathrm{Ns}]}{ }^{\mathrm{k}}$, is the transmitted $\mathrm{j}^{\text {th }}$ binary data bit and composed of equally likely bits for the $\mathrm{k}^{\text {th }}$ source, and $\mathrm{E}_{\mathrm{tx}}{ }^{\mathrm{k}}$ is the transmitted energy per pulse. $\mathrm{N}_{\mathrm{s}}$ is the number of pulses transmitted per bit, $T_{c}$ is the hop width and $C_{j}^{k}$ is the $T H$ code for the $k^{\text {th }}$ source, $C_{j}^{k} \epsilon$ $\left\{0,1, \ldots, N_{h}-1\right\}$, such that an additional time shift of " $\mathrm{C}_{\mathrm{j}}^{\mathrm{k}} \mathrm{T}_{\mathrm{c}}$ " is introduced when the $\mathrm{j}^{\text {th }}$ pulse is transmitted. $T_{f}$ is the frame duration, satisfying $T_{f}=N_{h} T_{c}$, the bit duration can be represented as $\mathrm{T}_{\mathrm{b}}=\mathrm{N}_{\mathrm{s}} \mathrm{T}_{\mathrm{f}}$ with bit energy $\mathrm{E}_{\mathrm{b}}$, and $\delta$ is the modulation index (the time shift added to a pulse with an optimal value of $20 \%$ of a pulse width [4]).

\section{B. The Multi-tone Interferer Model}

The NBI signal, $\mathrm{I}(\mathrm{t})$, is assumed to be the sum of " $\mathrm{N}_{\mathrm{i}}$ " tone interferers and it can be written as

$$
I(t)=\sum_{n=1}^{N_{i}} \sqrt{\frac{2 I}{N_{i}}} \cos \left(2 \pi f_{n}(t-\vartheta)+\varphi_{n}\right)
$$

where " $f_{n}$ " is the $n^{\text {th }}$ interference frequency, " $q$ " is a random time delay, and " $\varphi_{n}$ " are independent and identically distributed (i.i.d.) random phases due to modulation and i.i.d. symbols. I is the total transmitted power of the interference signal.

\section{The Multiple Access Interference}

Assuming all the users use the same pulse frame duration " $\mathrm{T}_{\mathrm{f}}$ ". The desired transmitter and receiver are perfectly synchronized, yet the other interfering users are asynchronous with the victim receiver.

The multi-path free impulse response of the channel for the link between user $\mathrm{k}$ and the desired receiver can be written as 


$$
h^{k}(t)=\alpha^{k} \delta\left(t-\tau^{k}\right)
$$

where $\alpha^{\mathrm{k}}$ and $\tau^{\mathrm{k}}$ are the channel gain coefficient and the associate channel time delay for the $\mathrm{k}^{\text {th }}$ user respectively. The time delays are assumed to be independent and identically uniformly distributed random variables over $\left[0, T_{f}\right)$, without loss of generality, we assume that $\tau^{1}=0$.

Figures 1 and 2 depict the scenario of operation for the victim UWB system operating in the presence of both NBI and multiple access interference (MAI) in a perfect power control (PPC) and imperfect power control (IPC) scenarios.

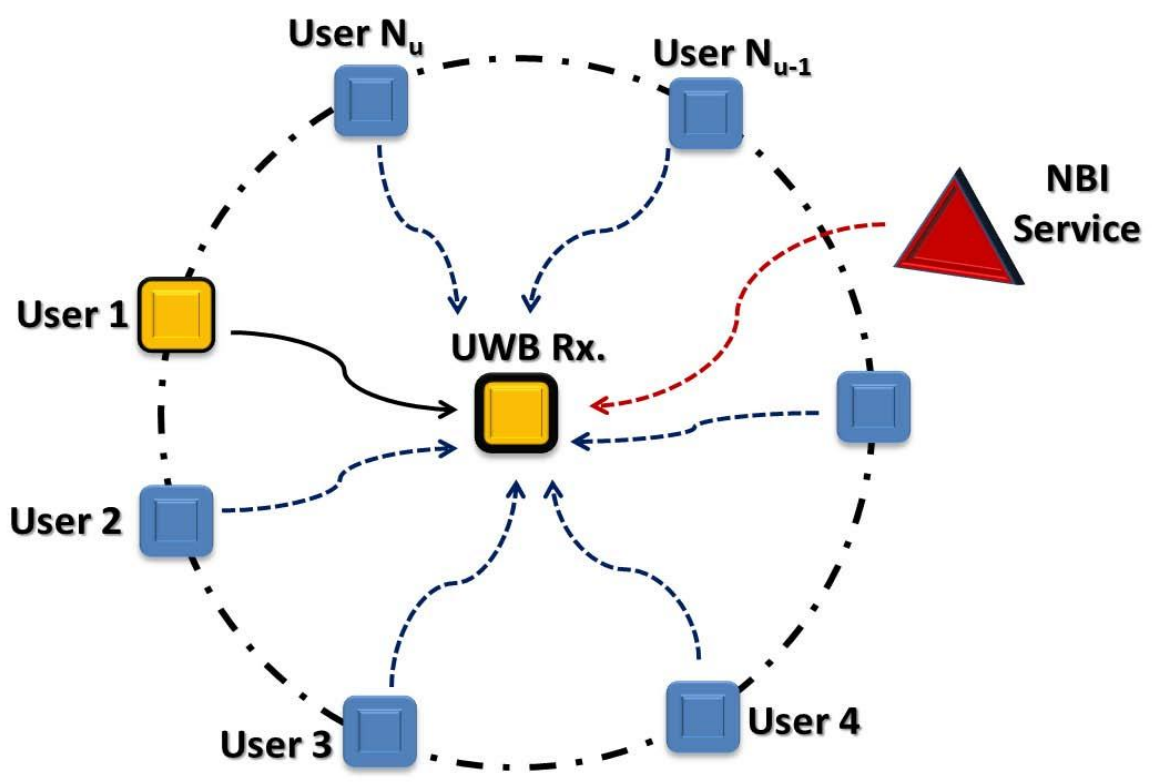

Fig. 1 The coexisting scenario with a network of interferers (NBI + PPC MAI).

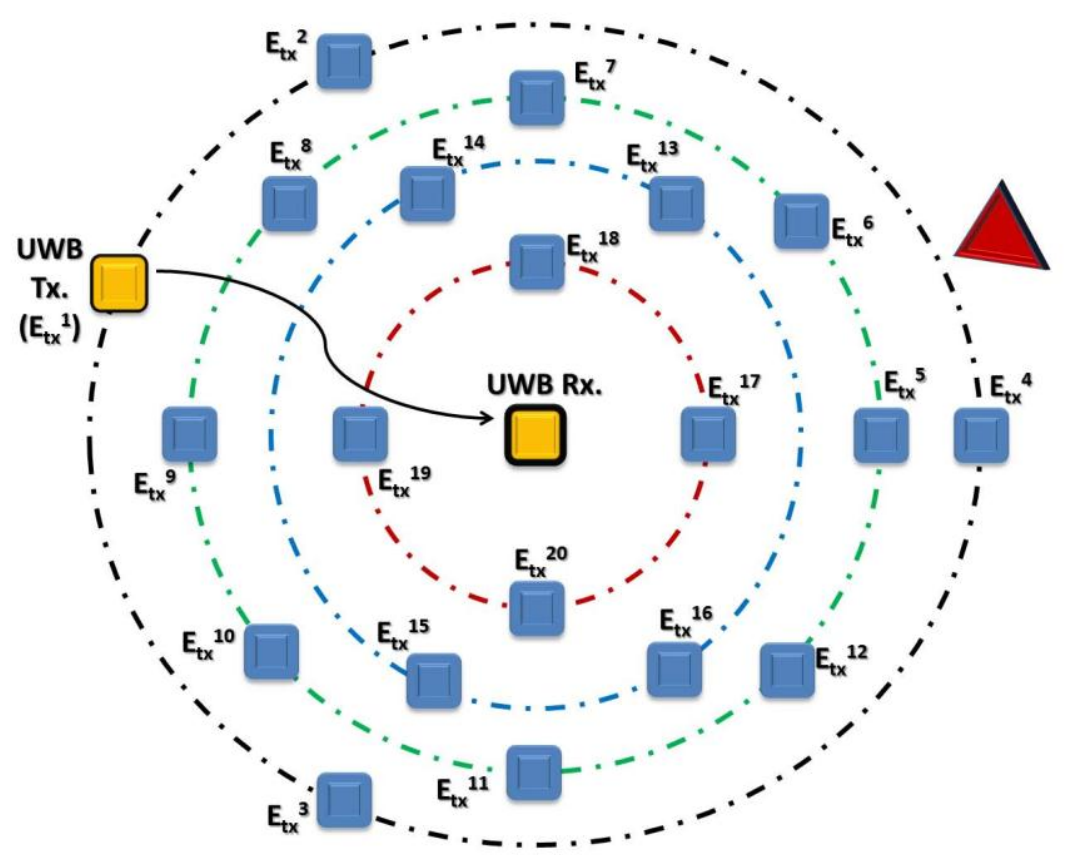

Fig. 2 The coexisting scenario with a network of interferers (NBI + IPC MAI). 


\section{The received signal}

Assuming a binary communication system in a single user case is considered and for a coherent correlation receiver with soft decision followed by Maximum Likelihood (ML) detector, the overall received signal, $r(t)$, for a TH-PPM UWB system in the presence of NBI and MAI can be written as

$$
r(t)=r_{d}(t)+r_{\text {mai }}(t)+I(t)+n(t)
$$

where, $n(t)$ is the AWGN with two sided power spectral density " $N_{o} / 2$ ".

The desired UWB received signal for the interval $[0, \mathrm{~Tb}]$ can be written as

$$
r_{d}(t)=\sum_{j=0}^{N_{S}-1} \sqrt{E_{r x}^{1}} p\left(t-j T_{f}-C_{j}^{1} T_{c}-\delta d_{j}^{1}\right)
$$

The MAI contribution for the same interval can be written as

$$
r_{\text {mai }}(t)=\sum_{k=2}^{N_{u}} \sum_{j=-\infty}^{\infty} \sqrt{E_{r x}^{k}} p\left(t-j T_{f}-C_{j}^{k} T_{c}-\delta d_{j}^{k}-\tau^{k}\right)
$$

where $\mathrm{E}_{\mathrm{rx}}{ }^{\mathrm{k}}$ is the received energy per pulse for the $\mathrm{k}^{\text {th }}$ user.

\section{Performance Analysis}

In this section, we evaluate the performance of a TH-PPM UWB system in the presence of NBI and MAI. It will be assumed that the channel is perfectly known at the receiver.

The correlation mask can be written as

$$
m(t)=\sum_{j=0}^{N_{s}-1}\left[p\left(t-j T_{f}-C_{j}^{1} T_{c}\right)-p\left(t-j T_{f}-C_{j}^{1} T_{c}-\delta\right)\right]
$$

The decision statistic can be written as

$$
\mathrm{Z}=\mathrm{S}_{\mathrm{d}}+\mathrm{S}_{\text {mai }}+\mathrm{I}_{\mathrm{N}}+\mathrm{n}
$$

where $S_{d}, S_{\text {mai }}, I_{N}$ and $n$ are the desired signal, MAI, NBI, and noise components respectively.

$$
S_{d}=\sqrt{E_{r x}^{1}} N_{s}(1-\rho)
$$

$\rho$ is the correlation coefficient between the two pulses $\mathrm{p}(\mathrm{t})$ and $\mathrm{p}(\mathrm{t}-\delta)$, for bits 0 and 1 respectively, $\rho$ can be written as

$$
\rho=\int_{-\infty}^{\infty} \mathrm{p}(\mathrm{t}) \mathrm{p}(\mathrm{t}-\delta) \mathrm{dt}, \quad \rho \in[-1,1]
$$

Assuming that the MAI follows a standard Gaussian approximation (SGA) hypothesis, the variance of the MAI component can be written as

$$
\sigma_{\text {mai }}^{2}=\sum_{\mathrm{k}=2}^{\mathrm{N}_{\mathrm{u}}}\left\{\frac{\mathrm{N}_{\mathrm{s}}}{\mathrm{T}_{\mathrm{f}}} \mathrm{E}_{\mathrm{rx}}^{\mathrm{k}} \int_{0}^{\mathrm{T}_{\mathrm{f}}}\left(\int_{0}^{2 \mathrm{~T}_{\mathrm{m}}} \mathrm{p}\left(\mathrm{t}-\tau^{\mathrm{k}}\right) \cdot \mathrm{m}(\mathrm{t}) \mathrm{dt}\right)^{2} \mathrm{~d} \tau^{\mathrm{k}}\right\}
$$


Since all delays are identically distributed

$$
\sigma_{\mathrm{mai}}^{2}=\frac{\mathrm{N}_{\mathrm{s}}}{\mathrm{T}_{\mathrm{f}}} \sigma_{\mathrm{m}}^{2} \sum_{\mathrm{k}=2}^{\mathrm{N}_{\mathrm{u}}} \mathrm{E}_{\mathrm{rx}}^{\mathrm{k}}
$$

where

$$
\sigma_{\mathrm{m}}^{2}=\int_{0}^{\mathrm{T}_{\mathrm{f}}}\left(\int_{0}^{2 \mathrm{~T}_{\mathrm{m}}} \mathrm{p}(\mathrm{t}-\tau) \cdot \mathrm{m}(\mathrm{t}) \mathrm{dt}\right)^{2} \mathrm{~d} \tau
$$

The interference term, $\mathrm{I}_{\mathrm{N}}$ can be written as

$$
\mathrm{I}_{\mathrm{N}}=\sum_{\mathrm{n}=1}^{\mathrm{N}_{\mathrm{i}}} \sqrt{\frac{2 \mathrm{I}}{\mathrm{N}_{\mathrm{i}}}}\left|\mathrm{M}\left(\mathrm{f}_{\mathrm{n}}\right)\right| \cos \left(\varphi_{\mathrm{n}}\right)
$$

The transfer function of the matched filter receiver can be written as $|\mathrm{M}(\mathrm{f})|=$ F.T. $\{\mathrm{m}(\mathrm{t})\}$, where F.T. $\{$.$\} represents the Fourier transform process, we can note that " \mathrm{M}(\mathrm{f})$ " depends on the used pulse waveforms. For a TH-PPM UWB system M(f) can be written as

$$
\begin{gathered}
|M(f)|=2|P(f)||\sin (\pi f \delta)| \sum_{k=0}^{N_{s}-1} \exp \left[j 2 \pi f\left(k T_{f}+C_{k} T_{c}\right)\right] \\
p(t)=\sqrt{\frac{640}{231 N_{s} \tau_{p}}}\left[1-12 \pi\left(\frac{t}{\tau_{p}}\right)^{2}+16 \pi^{2}\left(\frac{t}{\tau_{p}}\right)^{4}-\frac{64}{15} \pi^{3}\left(\frac{t}{\tau_{p}}\right)^{6}\right] \cdot \exp \left[-2 \pi\left(\frac{t}{\tau_{p}}\right)^{2}\right]
\end{gathered}
$$

where $\mathrm{P}(\mathrm{f})$ is the Fourier transform of the UWB pulse, $\mathrm{p}(\mathrm{t})$, which can be modeled as the six derivative Gaussian pulse presented in [5]

where $\tau_{\mathrm{p}}$ is the pulse shaping factor, then

$$
P(f)=\frac{8 \pi^{3}}{3 \sqrt{1155 N_{s}}} \cdot \tau_{p}^{13 / 2} \cdot f^{6} \cdot \exp \left(-\frac{\pi f^{2} \tau_{p}^{2}}{2}\right)
$$

Following the same approach as [5], the phase term $\left\{\arg \left[M\left(f_{n}\right)\right]+2 \pi f_{n}\left(t-\tau_{n}\right)\right\}$ is included within the random phase " $\varphi_{n}$ ", conditioned on the r.v. $\left|M\left(f_{n}\right)\right|$. The NBI term, "I $I_{N}$ " can be considered conditionally Gaussian with variance:

$$
\sigma_{i}^{2}=\sum_{n=1}^{N_{i}} \frac{I}{N} \cdot\left|M\left(f_{n}\right)\right|^{2}
$$

The variance of the noise can be written as

$$
\sigma_{\mathrm{N}}^{2}=\mathrm{N}_{\mathrm{s}} \mathrm{N}_{\mathrm{o}}(1-\rho)
$$

The total disturbance due to the NBI plus MAI plus noise can be considered conditionally Gaussian with variance $\left[\sigma_{\text {tot }}^{2}=\sigma_{i}^{2}+\sigma_{N}^{2}+\sigma_{\text {mai }}^{2}\right.$.

Finally, the TH-PPM BER can be written as

$$
\mathrm{P}_{\mathrm{e}}=\mathrm{Q}(\sqrt{\gamma})
$$


where, Q is the standard Q-function, and " $\gamma$ " is the signal to NBI plus MAI plus noise ratio $\gamma$ can be written as

$$
\gamma=\left[\left(\frac{E_{\mathrm{rx}}^{1}}{N_{\mathrm{o}}}(1-\rho)\right)^{-1}+\left(\frac{(1-\rho)^{2}}{\sigma_{\mathrm{m}}^{2} \cdot \mathrm{R}_{\mathrm{b}} \cdot \sum_{\mathrm{k}=2}^{\mathrm{N}_{\mathrm{u}}} \frac{\mathrm{E}_{\mathrm{rx}}^{1}}{\mathrm{E}_{\mathrm{rx}}^{\mathrm{k}}}}\right)^{-1}+\left(\frac{\operatorname{SIR} \cdot \mathrm{N}_{\mathrm{i}} \cdot(1-\rho)^{2}}{\sum_{\mathrm{n}=1}^{\mathrm{N}_{\mathrm{i}}}\left|\mathrm{M}\left(\mathrm{f}_{\mathrm{n}}\right)\right|^{2}}\right)^{-1}\right]
$$

where, SIR is the signal to interference ratio.

In a PPC scenario, the ratio

$$
\sum_{\mathrm{k}=2}^{\mathrm{N}_{\mathrm{u}}} \frac{\mathrm{E}_{\mathrm{rx}}^{\mathrm{k}}}{\mathrm{E}_{\mathrm{rx}}^{1}}=\mathrm{N}_{\mathrm{u}}-1
$$

Whereas in an IPC scenario, the following case will be investigated [6]:

$$
\left\{\begin{array}{c}
\mathrm{E}_{\mathrm{rx}}^{2}=\mathrm{E}_{\mathrm{rx}}^{3}=\mathrm{E}_{\mathrm{rx}}^{4}=\mathrm{E}_{\mathrm{rx}}^{1} \\
\mathrm{E}_{\mathrm{rx}}^{5}=\mathrm{E}_{\mathrm{rx}}^{6}=\mathrm{E}_{\mathrm{rx}}^{7}=\mathrm{E}_{\mathrm{rx}}^{8}=2 \mathrm{E}_{\mathrm{rx}}^{1} \\
\mathrm{E}_{\mathrm{rx}}^{9}=\mathrm{E}_{\mathrm{rx}}^{10}=\mathrm{E}_{\mathrm{rx}}^{11}=\mathrm{E}_{\mathrm{rx}}^{12}=2 \mathrm{E}_{\mathrm{rx}}^{1} \\
\mathrm{E}_{\mathrm{rx}}^{13}=\mathrm{E}_{\mathrm{rx}}^{14}=\mathrm{E}_{\mathrm{rx}}^{15}=\mathrm{E}_{\mathrm{rx}}^{16}=3 \mathrm{E}_{\mathrm{rx}}^{1} \\
\mathrm{E}_{\mathrm{rx}}^{17}=\mathrm{E}_{\mathrm{rx}}^{18}=\mathrm{E}_{\mathrm{rx}}^{19}=\mathrm{E}_{\mathrm{rx}}^{20}=4 \mathrm{E}_{\mathrm{rx}}^{1}
\end{array}\right\}
$$

\section{Numerical Results}

The analytic expressions developed in the previous section [equations (20) - (21)] will be used to evaluate the performance of the TH-PPM-UWB system under the impact of both NBI and MAI in AWGN channel.

We will consider a six derivative Gaussian received pulse with values: $\mathrm{T}_{\mathrm{m}}=0.5 \mathrm{~ns}, \tau_{\mathrm{p}}=0.192$ $\mathrm{ns}, \delta=0.068 \mathrm{~ns}, \rho=-0.824$, the chip width $\mathrm{T}_{\mathrm{c}}=1.5 \mathrm{~ns}$ and $\mathrm{R}_{\mathrm{b}}=20 \mathrm{Mbps}$. The NBI signal is modeled as the Wi-Fi 802.11a signal, with number of data carriers $\mathrm{N}_{\mathrm{i}}=52$ tones and center frequency $\mathrm{f}_{\mathrm{i}}=5.745 \mathrm{GHz}$.

Figure 3 depicts the performance of a TH-PPM system in the presence of MAI for different number of users ( $\mathrm{N}_{\mathrm{u}}=5,10$ and 20 users). The SNR degradation, due to MAI, is expected to reach up to $4 \mathrm{~dB}$ at a $\mathrm{BER}=1 \times 10^{-4}$.

Figure 4 depicts the impact of both NBI and MAI signals on the performance of a TH-PPM system for SIR $=-15$ and $-20 \mathrm{~dB}$ and for different number of users 5, 10 and 20. It can be seen that in the presence of 20 users and SIR $=-15 \mathrm{~dB}$, an additional SNR degradation, due to NBI, is expected to reach up to $5 \mathrm{~dB}$ at a $\mathrm{BER}=2 \times 10^{-3}$.

Figure 5 depicts the impact of MAI signal in a PPC and IPC scenarios for $\mathrm{N}_{\mathrm{u}}=20$ users, along with the presence of NBI signal for SIR $=-10$ and $-20 \mathrm{~dB}$. It can be seen that a SNR degradation is expected to reach up to $5 \mathrm{~dB}$ at a BER $=5 \times 10^{-3}$ due to IPC in a SIR $=-10 \mathrm{~dB}$.

Figure 6 depicts a comparison between the impact of NBI versus the impact of PPC MAI on the performance of TH-PPM system. It can be seen that the BER degradation is expected to reach up to 0.1 for $\mathrm{N}_{\mathrm{u}}=20$ users in the absence of NBI. Whereas, in the absence of MAI, the BER degradation is expected to reach up to $10^{-3}$ for changing the SIR from -10 to $-25 \mathrm{~dB}$. From these results we can conclude that, the NBI has more impact on the performance of THPPM UWB system compared to the MAI one. 


\section{Conclusions}

The goal of this paper was to drive an analytic closed form expression for the BER performance of TH-PPM UWB communication systems in presence of both NBI and MAI signals in AWGN channel. The MAI has been investigated in PPC and IPC scenarios. The NBI signal is approximated by the sum of independent asynchronous tone interferers with arbitrary frequencies.

It has been shown that the BER performance of the UWB communication system can be severely deteriorated due to the presence of both NBI and MAI signals. Also, we have proven that the NBI has a severe impact on the performance of a TH PPM UWB system compared to the MAI impact.

\section{References}

[1] Revision of Part 15 the Commissions Rules Regarding Ultra-Wideband Transmission Systems FCC, ET Docket 98-153, 2002.

[2] L. Zhao and A. M. Haimovich, “ Performance of ultra wideband communications in the presence of interference,” IEEE J. Select. Areas Commun., vol. 20, pp.1684-1691, Dec. 2002.

[3] M. Z. Win, R. A. Scholtz,“ Ultra-wide Bandwidth Time- Hopping Spread-Spectrum Impulse Radio for Wireless Multiple Access Communications", IEEE Transactions on Communications, vol. 48, No. 4, April 2000.

[4] F. Ramirez-Mireles, “ Signal Design For Ultra-Wideband Communications in Dense Multipath," IEEE Trans. Vehicular Technology, vol. 51, No. 6, pp. 1517-1521, November 2002.

[5] Ehab M. Shaheen and M. El-Tanany, "Narrowband Interference Impact on the Performance of UWB Communication Systems in Lognormal Flat Fading Channels" IEEE 71st Vehicular Technology Conference, VTC2010- Spring, 16-19 May 2010.

[6] G. Giancola, L. De Nardis and M. G. Di Benedetto, "Multi User Interference in PowerUnbalanced Ultra Wide Band Systems: Analysis and Verification," IEEE Conference on Ultra Wideband Systems and Technologies, pp. 325-329, 2003. 


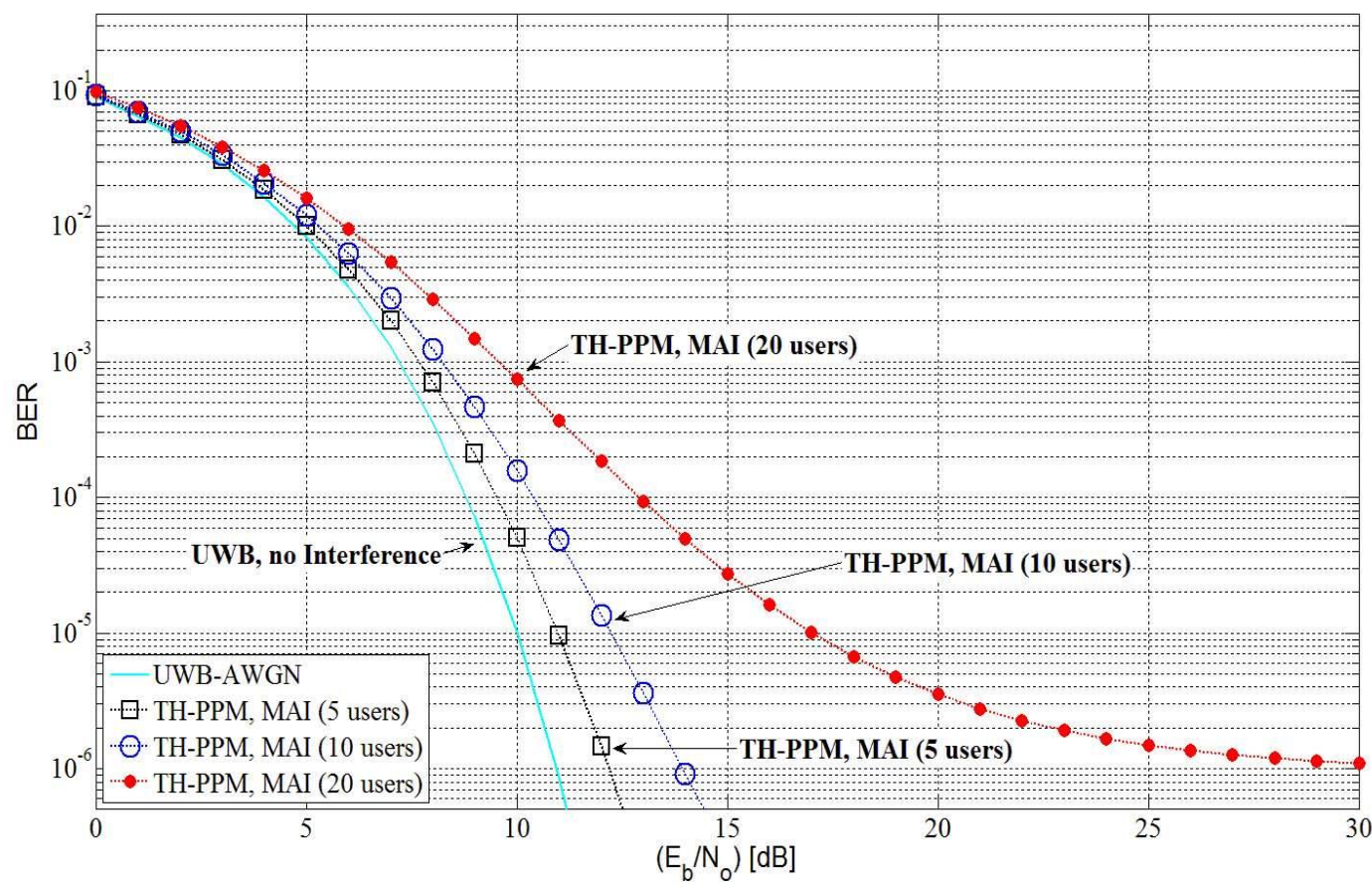

Fig. 3 BER performance of a TH-PPM system in the presence of MAI.

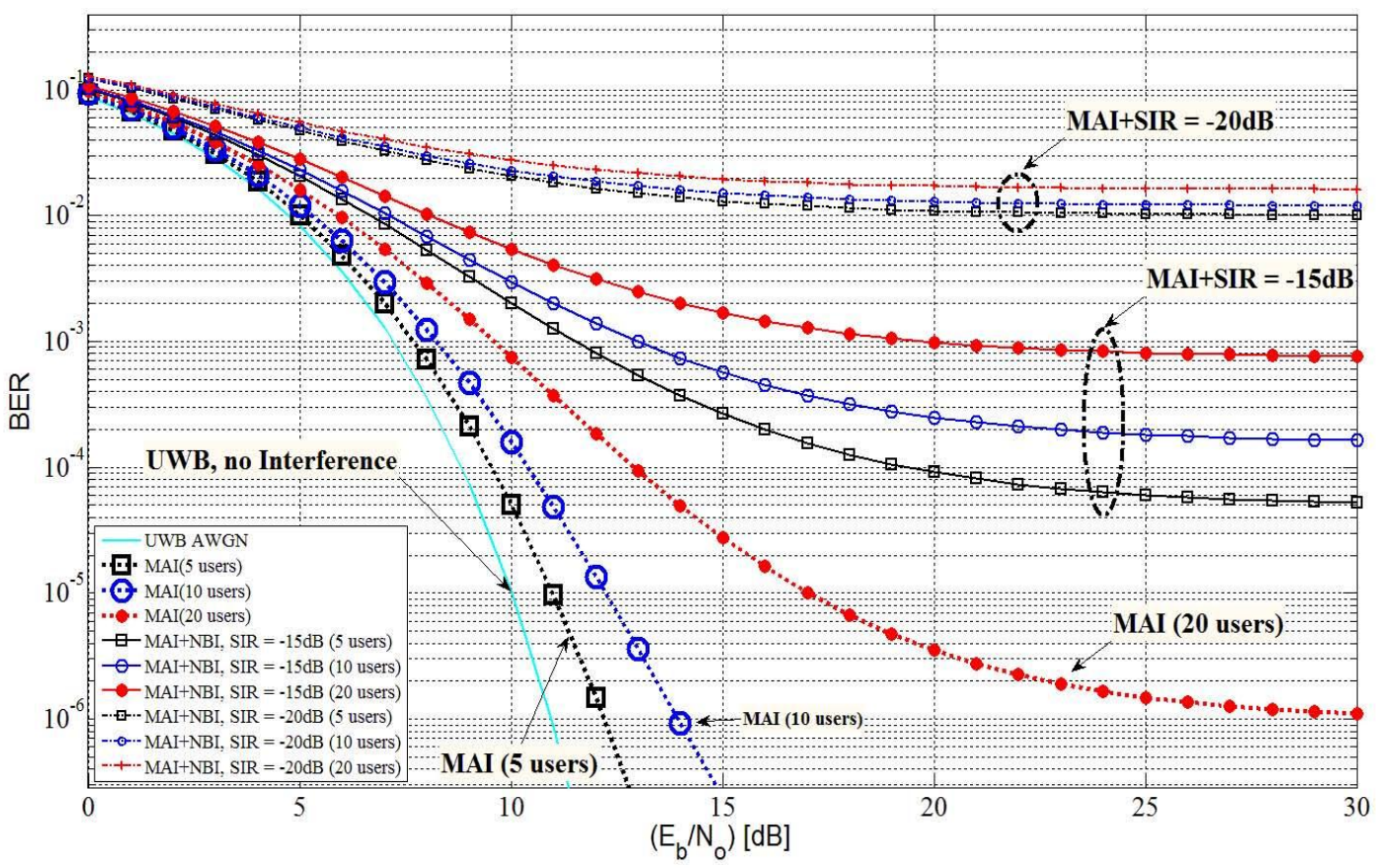

Fig. 4 BER performance of a TH-PPM system in the presence of PPC-MAI and NBI signals 


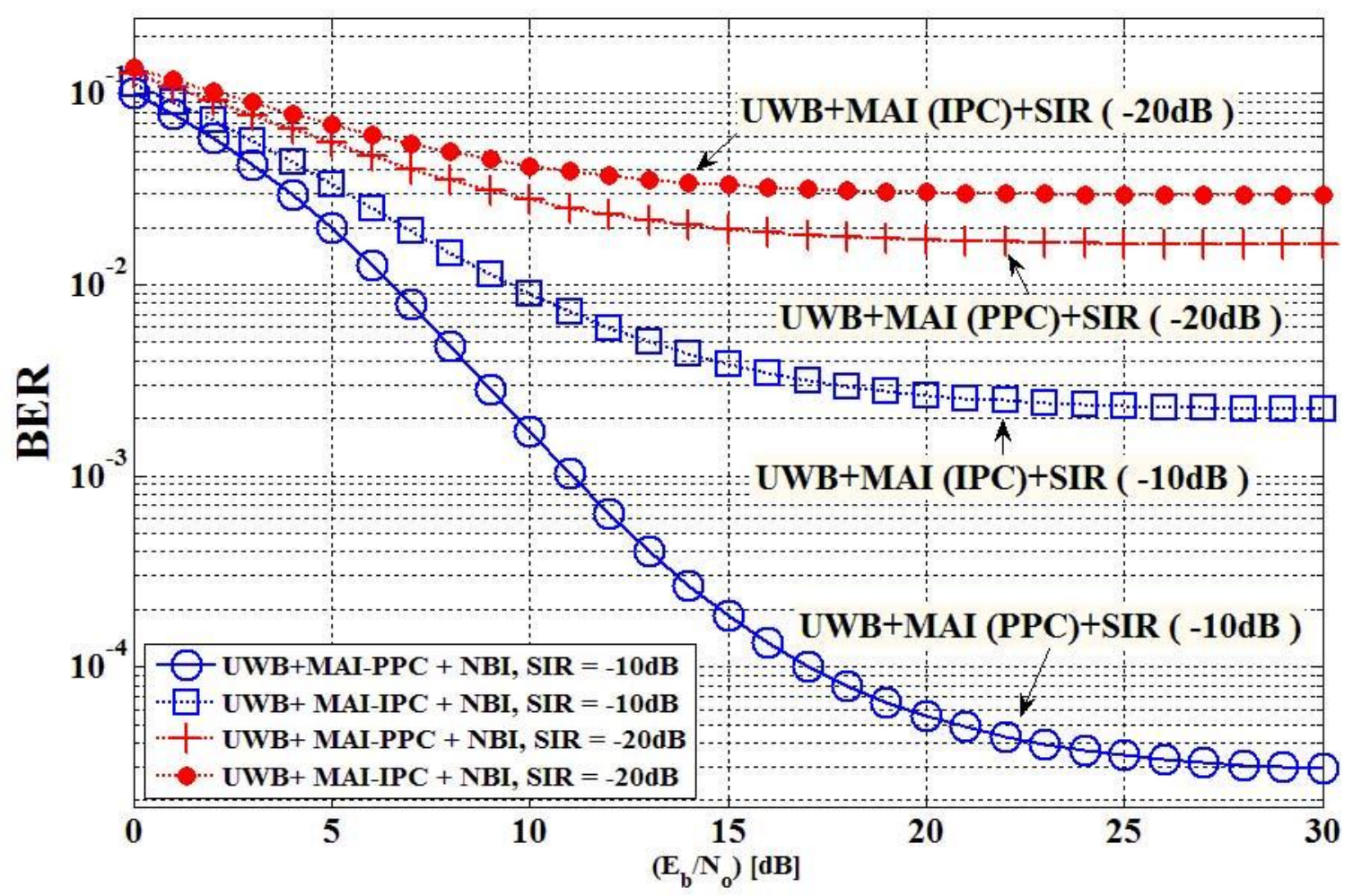

Fig. 5 BER performance of a TH-PPM system in the presence of PPC/IPC MAI and NBI signals

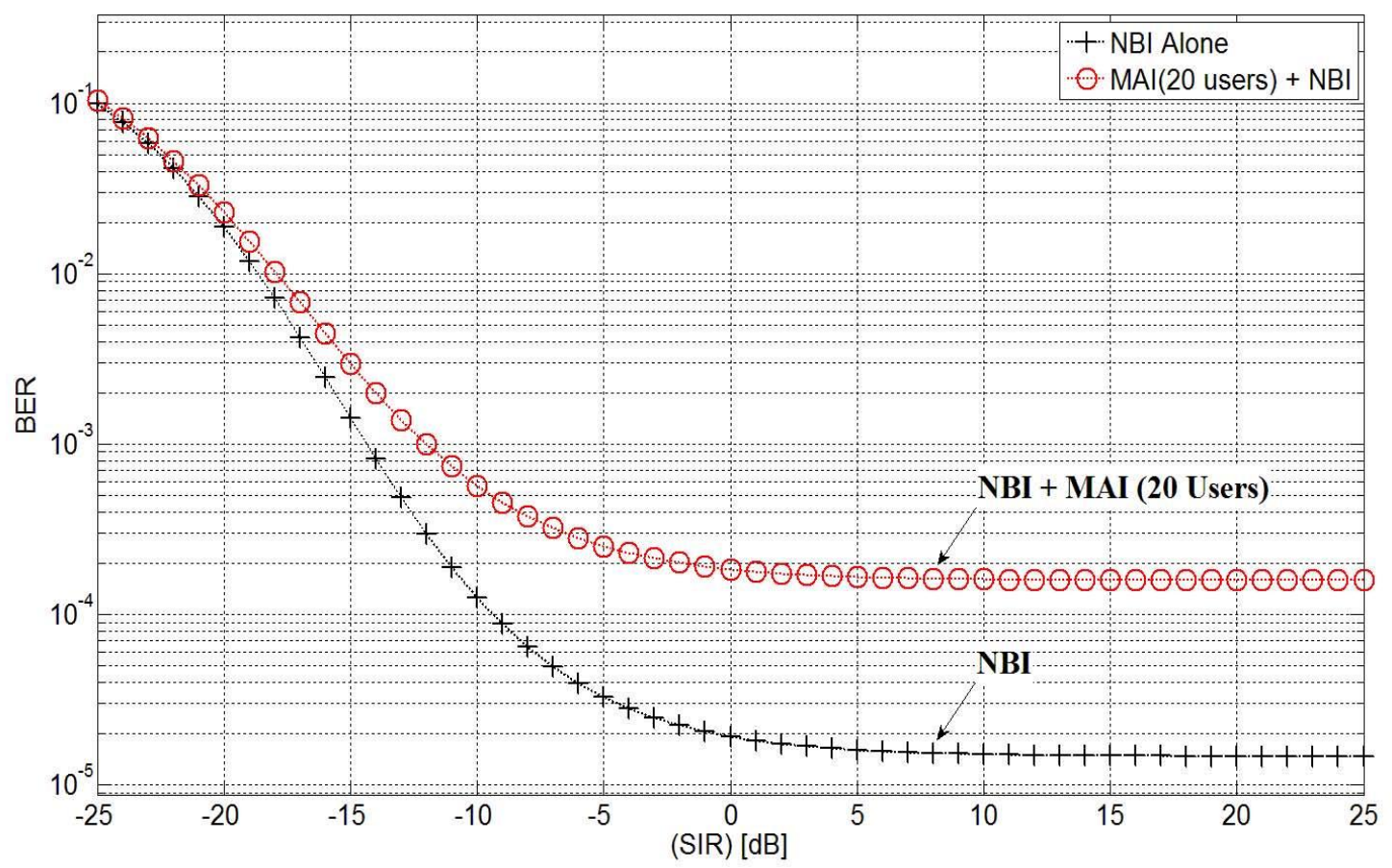

Fig. 6 The impact of NBI on the performance of a TH-PPM system, $E_{b} / \mathbf{N}_{0}=10 \mathrm{~dB}$ 